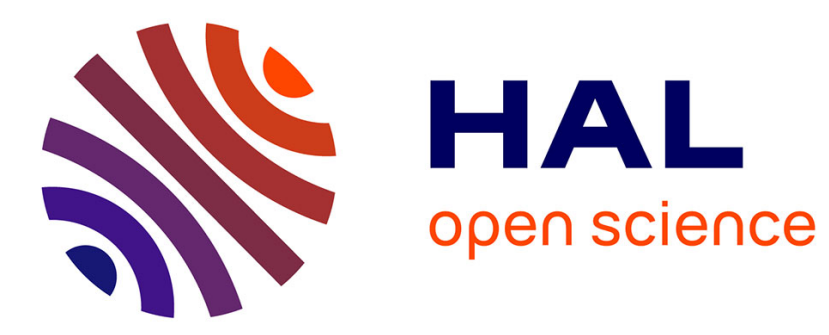

\title{
La mystique du climax
}

Henri Gaussen

\section{To cite this version:}

Henri Gaussen. La mystique du climax. Revue forestière française, 1964, 12, pp.946-947. 10.4267/2042/24616 . hal-03389952

\section{HAL Id: hal-03389952 \\ https://hal.science/hal-03389952}

Submitted on 21 Oct 2021

HAL is a multi-disciplinary open access archive for the deposit and dissemination of scientific research documents, whether they are published or not. The documents may come from teaching and research institutions in France or abroad, or from public or private research centers.
L'archive ouverte pluridisciplinaire HAL, est destinée au dépôt et à la diffusion de documents scientifiques de niveau recherche, publiés ou non, émanant des établissements d'enseignement et de recherche français ou étrangers, des laboratoires publics ou privés. 


\title{
LA MYSTIQUE DU CLIMAX
}

\author{
PAR
}

\author{
H. GAUSSEN
}

Professeur à l'Université de Toulouse

Je m'adresse ici aux forestiers des pays tempérés où on admet que le stade final stable de l'évolution d'un peuplement est la forêt " climax 》.

On lui prête toutes les vertus: elle reconstitue le groupement en équilibre avec le milieu; elle est incombustible; elle réalise l'idéal de beauté et de stabilité. Ces vertus sont-elles réelles? Il faut être modéré en toutes choses et $\mathrm{j}$ 'accorde volontiers un certain nombre de vertus au climax mais c'est souvent une vue théorique.

Il y a des forêts encore peu exploitées par l'homme et qui doivent réaliser le type icléal. Si nous allons aux Laurenticles, au Canada, le type idéal est un fouillis de petits arbres encombrés de près d'un mètre de détritus pourrissants. La valeur économique est réelle à cause de la densité des petits Sapins, Epicéas ou Bouleaux, mais c'est tout le contraire d'une belle forêt.

Allons chercher le climax splendide des forêts cle Douglas en Colombie britannique. Quelques coins sont sensationnels mais sur d'immenses étendues la forêt a brûlé. Ici elle a 20 ans, là 40 et les troncs noircis des grands arbres disparus forment un paysage sans attrait. Et n'accusons pas seulement l'homme. Ies forestiers canadiens estiment que $70 \%$ des incendies sont causés par la foudre, phénomène naturel.

Allons au N. de Melbourne où s'étalent les splendeurs des forêts d'Eucalyptus regnans. Un incendie naturel a dévasté des immensités, causé la mort de nombreuses personnes. L’Eucalyptus distille une essence inflammable et le vent porte la flamme d'arbre en arbre.

Et parlons des Pins, ces " romanichels " que le Conservateur Ducamp détestait cordialement. Et dire que A. Chevalier lui a dé- 
dié une section du genre Pinus, le Ducampopinus! Ils n'ont pas le droit d'être des climax. C'est en partie vrai, et il est incontestable que l'homme a favorisé l'extension de ces arbres. Mais il ne faut pas exagérer. Les analyses polliniques relatives à des périodes où la pression humaine était faible montrent des Pins partout.

Les immenses forêts de Pins sylvestres de Suède ne sont-elles pas des climax? Jes forêts de Pins à crochets ou de Pins Mugho n'auraient-elles pas le droit d'être des climax? Le Mexique a d'immenses forêts de Pins et presque cinquante espèces différentes de ce genre. J.es forêts brîlent constamment, surtout du fait de l'homme et, en mars-avril, de Mexico, on ne voit guère les géants du Popocatepetl et de l'Ixtaccihuatl. Ce sont en général des climax.

Aux Pyrénées, laissons la forêt de Hêtre-Sapin évoluer lentement vers le " climax ". Les Sapins étoufferont peu à peu les IYêtres puis seront seuls. La régénération deviendra peu à peu impossible; la forêt périra et la lande à Callune la remplacera. La lande est-elle le vertueux climax?

Et je n'ai pas encore abordé le côté économique. Le champ de blé épuise le sol et il est économique de mettre des engrais pour restituer au sol ce que l'homme a enlevé avec la récolte.

Un champ de Pins maritimes rapporte de l'argent, il appauvrit le sol. N'a-t-on pas le droit de cultiver un champ de Pins maritimes, quitte à restituer an sol ce qui a été enlevé et à lıi donner les qualités nécessaires à une nouvelle récolte?

En bien des points de France, l'évolution normale évincerait les Pins pour donner une forêt de Chênes qui aurait toutes les vertus climaciques. Mais tant que les chimistes ne sauront pas faire à hon marché du papier avec les Chênes, les Pins rapporteront hien clavantage.

J'ai fait longtemps partie de la "Silva Mediterranea " qui théoriquement n'est pas morte. Nous voulions étudier les forêts méditerranéennes, restaurer la couverture d'Yeuses ou de Cyprès. Mais les considérations économiques ont balayé nos rêves; on ne parle plus que de Peupliers et d'Eucalyptus et un peu de Chênes-lièges.

Un forestier éminent a dit du Jura: quand les Epicéas deviennent beaux, c'est qu'on quitte le Picetum, c'est-à-dire le climax de l'Epicéa. Il parait en effet que les Pessières du Jura sont des hêtraies quand elles sont helles. Y a-t-il des forestiers pour vouloir remplacer l'Epicéa par le Hêtre? Ce serait botaniquement l'idéal; est-ce l'idéal du forestier qui gagne de l'argent avec l'Epicéa et offre au touriste de magnifiques cathédrales de verdure? 